\title{
O Instituto Internacional de Ciências Administrativas (*)
}

\section{Luís Simões Lopes}

SR. Presidente, Sirs. Ccinselheiros. Estou obedecendo a uma ordem, que recebi do nosso ilustre Secretário e Presidente desta sessão, para falar um pouco a respeito do Instituto Internacional de Ciências Administrativas.

A matéria é de interêsse restrito, é assuntc da órbita daqueles que vêm tendo a sua curiosidade despertada para o progresso das ciências administrativas no mundo.

O que quero acentuar, através destas palavras, é que a idéia do aperfeiçoamento da administração, pública e privada, vem ganhando corpo de tal maneira que, hoje, o Instituto Internacicinal de Ciências Administrativas já congrega em seu seio um grande número de países; nas suas reuniões, mesas-redondas e, principalmente, nos Congressos que vem realizando, já tem tido oportunidade de reunir quase tantos países quanto as Nações Unidas. Isto demonstra nos meic:3 internacionais, o reconhecimento da necessidade da melhoria da administração, especialmente da administração pública, indispensável ao progresso das nações e à felicidade do povo, em virtude da ingerência cada vez mais profunda do Estado na vida moderna.

Começarei por abcrdar as origens e objetivos gerais do Instituto Internacional de Ciências Administrativas e suas características.

A Comissão Permanente dos Congressos Internacionais de Ciências Administrativas, criada em 1910, foi substituída, vinte anos depois, pelo atual Instituto Internacional de Ciências Administrativas.

Destarte, 1930 indica uma etapa decisiva na evoluçãc dos organismos internacionais vinculados à pesquisa, análise, documentação e assistência técnica no campo dos problemas sociais em geral, e da Administração em particular. Em 1930 são aprovados e divulgados os estatutos da única associação internacional que tem como objetivos fundamentais:

- o desenvolvimento das ciências administrativas;

- a melhoria das condições de funcionamento da administração pública, nos diversos países;

(*) Conferência pronunciada sob os auspícios da Confederação Nacional do Comércio. Carta Mensal do Conselho Técnico da Confederação Nacional do Comércio - Fevereiro de 1958, N. ${ }^{\circ} 35$ - Rio de Janeiro. 
- o aperfeiçoamento dos métodos, técnicas, doutrinas e práticas administrativas;

-.. o progresso da administração internacional.

Após o advento das Nações Unidas, passou-se a considerar como um novo campo, dentro da ciência da administração, a administração internacional. Eu próprio, durante longos anos, fui membro de um comitê das Nações Unidas, Composto de grandes nomes com exceção do orador, naturalmente (nãc apoiador), especializados em problemas de administração, escolhidos em vários países. Êsse comitê se dedica ao estudo do aperfeiçoamento da administração internacional. Trata-se, por conseguinte, como disse, de um novo setor dentro da ciência da administração.

As atribuições, iniciativas e atividades do Instituto Internacional de Ciências Administrativas vêm, desde então, se ampliando e fortalecendo, através da freqüente realização de mesas-redondas e congressos internacionais, durante os quais se efetua um poderoso intercâmbio de experiências nacionais, - teóricas e práticas - no âmbito da Administração.

A medida que se ampliam os horizontes da atuação dos governos e das emprêsas modernas, crescem e se complicam, de maneira imprevista, as áreas cu domínios e os próprios instrumentos da Administração (pública e privada), em função do crescente dinamismo das estruturas sociais. As oscilações da conjuntura econômica e scicial, observadas em todos os países; vários fatôres de perturbação, expansão demográfica, desequilíbrios políticos, exacerbações sociais, imprevistas mutações, recuos e avanços econômicos, progressos culturais e tecnológicos - em síntese, todo o desconcertante emaranhado de problemas que desafiam a capacidade dos homens de govêrno e dos homens de emprêsa teriam forçosamente de modificar e transformar o equacionamentc, o estilo, as técnicas, instrumentos e perspectivas ia Administração, compelida a se adaptar, em cada Nação, às novas condições do meio ecológico, do ambiente, da época, dos desenvolvimentos científicos, técnicos e culturais predcminantes.

Assim, o exame comparativo das experiências realizadas nesse domínio - ao mesmo tempo tão velho e tão novo - a realização de inquéritos, estudos, projetos e arrojadas iniciativas tendentes ao aperfeiçoamento da ciência administrativa, - como, por exemplo, as teorias e práticas mais recentes de mecanização e automatismo do trabalho e da produção dos países altamente industrializados - enfim, essa transformação que se opera, em ritmo surpreendente, em todos os setores ou segmentos da vida contemporânea - na família, nas escolas, nas fazendas, nos sindicatos, nas fábricas, na igreja, nos escritórios, nos partidos, nos organismos governamentais de qualquer nível - tôda essa transformação encontra no Instituto Internacional de Ciências Administrativas um centro internacional de investigação, documentação e intercâmbio de singular importância. Promovendo estudos, coligindo dados, permutando contribuições, comparando sistemas, formulando sugestões, prestando assistência técnica, vem o Instituto Internacional de Ciências Administrativas desde 1930 realizando obra de tal envergadura, que conseguiu obter a adesão de mais de 40 países aos seus Estatutos, periòdicamente renovados. Êsses países, na qualidade de 
Estadcs-Membros, por sua vez organizam seções nacionais do Instituto como em nossa terra, o Instituto Brasileiro de Ciências Administrativas para realização de programas ou objetivos similares. Em virtude de suas rontribuições positivas como laboratório de soluções modernas para os problemas administrativos em geral, fonte de preciosos ensinamentos, esccia e fator de modernização - por todos êsses motivos, goza o Instituto das vantagens do Estatuto Cćnsultivo junto à Unesco e ao Conselho Econômico e social das Nações Unidas; participa ativamente dos trabalhos dessas organizações, referentes às suas atividades, e se encontra prestigiado pelos governos e instituições técnico-culturais dos países mais adiantados do mundo.

Estrutura e funcionamento do Instituto Internacional de Ciências Administrativas.

São Órgãos do Instituto:

1 - A Assembléia-Geral que compreende o conjunto dos delegados oficiais dos Estados-Membros e dos membros individuais e coletivos. A Assembléia-Geral se reúne todos cs três anos, simultâneamente com os grandes Congressos Internacionais promovidos pelc Instituto.

2 - Conselho de Administração que se reúne anualmente para deliberar sôbre o orçamento da entidade, suas responsabilidades e contas; estabelece a política geral, a orientação e os programas do Instituto. O Conselho de Administração é constituído de representantes das Seções Nacionais e Internacionais representantes do Estados-Membros e dos presidentes dos Comitês Permanentes. O Conselho de Administração designa os dirigentes do Instituto e elege, entre os seus Membros, o Presidente e os 4 Vice-Presidentes, os quais conjuntamente com c's Presidentes dos Comitês Permanente, constituem o Comitê Executivo incumbido de realizar os programas do Instituto. Êsse Comitê deve se reunir pelo menos duas vêzes por ano. E' a seguirte a composição atual do Comitê Executivo:

a) Presidente: Sr. Frants Hvass, Embaixador da Dinamarca na Alemanha (Bonn), Chefe da Missão Militar Dinamarquesa na Alemanha;

b) Vice-Presidentes: Srs. Gerrit Abraham von PoelJe, Conselheiro de Estado na Alemanha; Albert T. DAy, ex-chefe do National Whitley Ccuncil, Inglaterra; Henry Matron, 1. ${ }^{\circ}$ Presidente Honorário do Tribunal de Contas da Bélgica; Luís Simões LoPES, Presidente da Fundação Getúlio Vargas e do Instituto Brasileiro de Ciências Administrativas;

c) Presidentes dos Comitês Permanentes: Srs. Henry Puget, Conselheiro de Estado, França; Willinam Finann, Diretor-Assistente da Organização e Métcdos, Bureau do Orçamento, Estados Unidos; ANDRÉ Molitor, Díretor-Geral, Ministério da Instrução Pública, Bélgica; 
d) Diretor-Geral do Instituto: Sr. Paul Schillings, e Tesoureiro, Sr. EDMON LESOIR, Bélgica.

É bastante simples e descentralizada a estrutura do Instituto Internacional de Ciências Administrativas, cujos objetivos sãc atingidos pelo esfôrço conjunto dos Membros, da seguinte forma:

I - Estadcis-Membros, isto é, Governos dos países que aderiram ao Instituto e que são, entre cutros, os seguintes: Alemanha, Áustria, Bélgica, Brasil, Dinamarca, Egito, Espanha, França, Grécia, Honduras, Israel, Itália, Japão, Líbano, Liechtenstein, Luxemburgo, México, Mônaco, Noruega, Países Baixos, Portugal, São Marinho, Suíça, Tailândia, Turquia, Caticano, Viet-Nam e Iugoslávia.

Êsses países encorajam o Instituto em suas atividades, proporcionando-lhe apoio moral e material; contribuem para manutenção da entiCade, na medida das contribuições arbitradas pelos respectivos Governos.

II - Seções Nacionais - Diversos Países-Membros organizaram Seçōes Nacionais como é o caso dc Chile, Coréia, América do Norte, Finlândia, India, Polônia e Inglaterra e, finalmente, do Brasil. Em nosso país, a Seção Nacional do Instituto Internacional é o Instituto Brasileiro de Ciências Administrativas. A característica das Seções Nacionais é que elas reunem professôres, técnicos e administradores, especialistas em assuntos de administração pública, a fim de discutir c's seus problemas à luz dos interêsses e peculiaridades dos respectivos países. Em alguns casos, as Seções Nacionais estãc evoluindo de maneira a se transformarem em órgãos não sòmente de pesquisas como de assistência técnica e consulta, quando citados.

III - As Seções Internacionais são constituídas pelos funcionários dos organismos internacionais que se consagram a estudos de assuntos de problemas específicos, principalmente dos problemas decorrentes do exercício de funções públicas internacionais.

IV - Membros Coletivcs são as instituições ou associações legalmente constituídas - tanto no plano nacional como internacional com finalidades afins às do Instituto e com êle colaboram. E' o caso, por exemplc; de inúmeras Universidades que desta forma se associam às atividades do Instituto.

$\mathrm{V}$ - Membros Individuais ou Titulares são as personalidades de primeiro plano que, em caráter individual, nos países onde ainda não existe uma Seção Nacional, se credenciam, pelos seus títulos profissicnais ou atividades científicas, no campo da administração. Allguns altos funcionários internacionais são também admitidos nessa qualidade.

VI - Mas as finalidades do Instituto são atingidas, de preferência, pela atuação dos seus Comitês Básicos:

a) o Comitê Científicc.

b) o Comitê de Práticas Administrativas. 
Aproveito para fazer uma breve digressão e explicar uma evolução muito curiosa que se passou no Instituto. O Instituto Internacional de Ciências Administrativas era uma instituição puramente européia, no início de sua fundaçãc. Dessa forma, a preocupação predominante refletia o pensamento europeu da época, em que a ciência da administração era tratada quase que só e ùnicamente do ponto de vista jurídico. Era mais o estudo da legislação vigente nos vários países, de direito comparado; nãc havia sido introduzida na mentalidade dos criadores e instituidores do Instituto a idéia que depois frutificou, principalmente com a vinda $\mathrm{d}$ c's americanos e com certa predominância que êles adquiriram no funcionamento do Instituto. Foi, então, o Instituto dividido em dois ccmitês fundamentais: a) o que se passou a chamar $\mathrm{C}$ cmitê Científico, que se ocupa precìpuamente dos problemas científicos da administração e particularmente, da parte jurídica; b) o Comitê chamado de Práticas Administrativas.

No Comitê Científico continuam predominando os europeus e, no de Práticas Administrativas, têm-se destacado os norte-americanos.

O Comitê Científico é constituída no momento, por cêrca de 30 membros, escolhidos de maneira a representar os diferentes sistemas administrativos. Os seus objetivos fundamentais podem ser resumidos em poucas palavras:

a) o estudo dos problemas de direitc administrativo, da estrutura e organização geral dos serviços administrativos;

b) o estudo dos métodos administrativos considerados sob a aspecto científico.

O Comitê de Práticas Administrativas abrange, por sua vez, no momento, representantes de 46 países e 8 Organizações Internacionais. Suas atribuições: são, em resumc; as seguintes:

- o estudo, no plano técnico, de todos os problemas de organização e métcdos, tendo em vista, notadamente, os casos concretos da administração dos diversos países; os processos em vigor; as melhorias ou aperfeiçoamentos que podem ser introduzidos no funcionamento dc's serviços, os progressos nas relações internas com o pessoal e assim por diante.

Incumbe, ainda, ao Comitê de Práticas Administrativas, promover o intercâmbio das informações no âmbito internacional, quanto aos aperfeiçcamentos que se observam na administração dos diversos países, inclusive das organizações internacionais.

Existe ainda um terceiro Comitê, denominado o Comitê dos Contratós, composto de 1 Presidente e de 4 Membros. Mas as atribuições dêsse Ccmitê dizem respeito à negociação dos contratos de trabalho ou pesquisas efetuados por conta de outros organismos, tais como a ONU, a UNESCO, a Fundação Ford.

O Sr. Octávio Bulhões - Onde é a sede?

O Sr. Luís Simốes Lopes - A sede do Instituto é em Bruxelas.

O Sr. OCtÁvio Bulhões - O Presidente é obrigado a permanecer lá? 
O Sr. Luís Simões Lopes - Lá existe a Direção-Geral; um DiretorExecutivo e o Secretariado. As reuniões do Instituto são sempre fora de Bruxelas, mas a sede permanente é naquela cidade.

Reuniões, serviços e atividades básicas do Instituto:

O I Congresso Internacional de Ciências Administrativas, levado a efeito na Bélgica, em 1910, estabeleceu uma Comissão permanente incumbida de organizar Congressos Internacionais, sucessivamente realizados em Bruxelas (1923), Paris (1927), Madrid (1930). Neste último Congresso é que surgiu o Instituto Internacional com as características que configuram a sua atual fisionomia. Desde então, tiveram prosseguimento, sob a direta responsabilidade do Instituto, os C cingressos Internacionais de Viena (1933), Varsóvia (1936), Berna (1947), Florença (1950), Istambul (1953). O Congresso de 1956 realizou-se ncvamente em Madrid, reunindo com êxito invulgar, representantes de 60 países, 8 organizações internacionais e mais de 400 participantes.

No intervalo dos ccngressos trienais, o Instituto Internacional promove mesas-redondas anuais.

Uma das reivindicações dos Delegados do Brasil junto ao Instituto é a realização de pelo menos uma mesa-redonda da entidade no Brasil desde que haja concordância dc nosso Govêrno - senão de um próprio Congresso Internacional. As mesas-redondas são mais fáceis de realizar, exigindo menores despesas do Govêrno hospedeiro. Se atendida essa nossa reivindicação, será a primeira reunião realizada na América. Até agcra só houve reuniões na Europa e na Ásia.

- O Sr. Antônio Camilo de Oliveira - Quais são as línguas de trabalho?

O Sr. Luís Simões Lopes - As línguas oficiais de trabalho vinham sendo o inglês e o francês. Entretanto, por proposta da delegação brasileira, em Madrid, com o apoio dos países latino-americanos, da Espanha e de Portugal, conseguimos também que fôsse incluído o espanhol como língua oficial, já que o português seria muito mais difícil de se conseguir, dado que é o idioma falado em dois países membros apenas.

O Sr. Antônio CAMILo de Oliveira - Os documentos são publicados nas duas línguas?

O Sr. Luís Simões Lopes - São publicados nas três línguas; a partir do Congresso de Madrid. Antes eram publicados em inglês e francês.

Como dizia, no intervalo dos Congressos trienais, o Instituto Internacional promove mesas-redondas anuais, a fim de aperfeiçoar o funcionamentn dos seus Comitês Permanentes e órgãc's dirigentes e preparar os futuros Congressos; examinar problemas concretos que, pela sua oportunidade e impontância, merecem uma atenção espedial. As mesas-redondas e as Reuniões Regionais constituem outro exemplo das atividades fundamentais do Instituto. Em Rangoon, por exemplo, sob os auspícios do Govêrno da Birmânia. teve lugar uma dessas Reuniões Regionais que funciona como um Seminário para o estudo dés problemas do Govêrno e Administração dêsse país. Outra Reunião dêsse tipo teve lugar nas Nações Unidas com 
- objetivo de estudar, em profundidade, os problemas de organização e gestão das emprêsas ou serviços industriais do Estado Moderno.

As Nações Unidas têm mostrado simpatia por êsses problemas. Nós mesmos, da Fundação Getúlio Vargas, conseguimos uma reunião especial sob a égide das Nações Unidas, para o estudo de um projetc que apresentamos do estabelecimento do ensino sistemático de Administração no Brasil. As Nações Unidas concordaram em patrocinar essa mesa-redonda que se realizou na antiga sede de Lake Success, em Ncrva Iorque, onde o então chamado "Projeto Brasileiro" foi estudado e, finalmente, aprovado com algumas modificações. Êsse projeto foi posteriormente realizado nc Brasil pela Fundação Getúlio Vargas, com a criação da primeira escola de administração pública instalada na América Latina.

Mais tarde, baseada nesse mesmo estudo, a Fundação instalou uma esccla de Administração de Emprêsas, que foi também a primeira escola no gênero, em moldes modernos, instalada na América Latina. Funciona essa escola em São Paulo sob a denominação de Escola de Administração de Emprêsas de São Paulo.

As mesas-redondas mais impcrtantes até agora efetuadas foram, pela ordem cronológica, as de Paris (1934), Berlim-Varsóvia-Zurich (1936), no Castelo d'Ardenne, na Bélgica (1937), em Bucareste (1938). Depois da guerra, realizaram-se mesas redondas em Copenhague (1948), Lisboa (1949), Nice-Mônaco (1951), Knocke (1952), Haia (1954), Oxford (1955) e, finalmente, em Opatija (1957).

O Brasil tem participado dessas reuniões por intermédio de delegações que têm conseguidc honrar, no exterior, as tradições nacionais de cultura e profundo interêsse pelo estudo das Ciências Administrativas.

De rossas delegações têm feito parte o nosso eminente companheiro Dr. Carlos Medeiros da Silva; os ilustres Drs. Themístocles Cavalcante, Gonçalves de Oliveira, Arizio de Viana, Guilherme de aragão, Diretor Geral do D.A.S.P., Caio TACito, D. BeAtriz Wahrlich, etc.

Atualmente, em virtude da própria ampliação de sua base geográfica, ccm a adesão de contingente cada vez maior de países e organismos internacionais, e por fôrça da crescente importância dos prcblemas administrativos, o Instituto Internacional se encontra em uma fase de acentuado dinamismo. E' relevante o número das suas atividades:

- um Secretário bem equipado;

- Serviços de traduçãa em francês, inglês e espanhol;

- um importante centro de documentação especializado;

- publicações periódicas de grande valor, dentre as quais se destacam:

a) A Révue Internationale des Sciences Administratives, órgão oficial do Instituto;

b) Documentos, monografias e publicações diversas, de cunho científico, tôdas assaz conhecidas. 
As atividades de cooperação internacional do Instituto se desenvoivem com intensidade, no quadro dos acôrdos firmados a respeito com a Secretariado Geral das Nações Unidas. Seria ocioso enumerar todos os estudos, pesquisas, projetos e trabalhos já preparados pelo Instituto, em colaboraçäo com os diversos organismos internacionais.

Quero, finalmente, fazer breves referências à última Reunião do Instituto, realizada em Opatija, Iugoslávia, no corrente ano.

Participaram dessa Reunião 32 países e duas Organizações Internacionais. Foi até uma surprêsa, porque, em geral, as mesas-redondas reunem número mencr de países. Mas êsse grande comparecimento se deve ac interêsse extraordinário, seja dos Estados-Membros, seja dos outros países que, não sendo membros, mandam sempre observadores.

Compareceram a República Federal da Alemanha, Bélgica, Brasil, Cambódia, Canadá, Ceilão, Chile, Dinamarca, Egito, Espanha, Estados Unidos da América do Norte, Filipinas, Finlândia, França, Grã-Bretanha, Holanda, India, Itália, Israel, Iugoslávia, Japão, Libéria, Líbia, México Noruega, Polônia, Portugal, Suécia, Suíça, Tailândia, Turquia e Uniãc Soviética, e as organizações internacionais, Centro de Informações de Belgrado Iugoslávia - e Nações Unidas.

Os três tópicos da mesa-redonda foram os seguintes:

a) tendências atuais com relação à transferência de podêres de autoridades maiores para autoridades menores delas separadas e viceversa;

b) automatização e seus aspectos de relevância para repartições públicas;

c) c sistema do mérito com relação à promoção de funcionários públicos, especialmente no que se refere à avaliação de eficiência.

Sôbre os itens a e c foram apresentadas várias monografias. No primeiro dia da reunião, foram distribuídos um relatório geral sôbre o primeiro daqueles tópicos e outro sôbre o segunda dêles, nos quais se condensavam as principais observações contidas nas referidas monografias e teses.

Desejava fazer uma referência ao item b, sôbre a automatização. A falta de melhor nome, está aqui autcmatização, que corresponde a automation em inglês. São processos novos que não podem ser chamados de mecanização, porque são muitos mais do que isso. Em resumo, é a aplicação ultra-recente dos chamados cérebros eletrônicos nos problemas da administração, não só na estatística, como de outra natureza. A autc'matização caminha ràpidamente, em alguns centros de pesquisas: ao mesmo tempo, é matéria pouco conhecida, não só no Brasil como também na grande maioria dos países, mesmo nos mais avançados. Por isso não pôde ser objeto de discussão; não haveria, provàvelmente, entre os presentes, quem a discutisse com real conhecimento de causa. Adotou, então, o Instituto, pela primeira vez - e penso que muito acertadamente - 0 critério de convidar um grupo de especialistas para fazer dissertações sôbre a matéria. As dissertações causaram forte impressão entre os participantes 
do Congresso. Estou certo de que o método foi acertado e poderá ser adotado com proveito em outras reuniões de caráter internacional ou nacional, sempre que se abordar assunto ncvo e complexo. Realmente, em matéria tão altamente especializada e tão pouco conhecida é improfícuo promoverem-se debates. Muito mais interessante é ouvir a palavra das poucas pessoas que podem falar com proficiência sôbre a matéria. De minha parte, fiquei tão interessado no assunto, do que pouco conhecia, através de leituras mais ou menos vagas, que estou empenhado em ver se conseguimos dar um primeiro passo no Brasil. Acho que êste primeiro passo deveria consistir em se reunirem algumas entidades que dispusessem de algum recurso para trazer ao país, por dois ou três meses, êsses especialistas ou outros, para tomarem contato com vários setores brasileiros e fazerem uma série de trabalhos preliminares.

O Brasil vai realizar o seu próximo censo em 1960 e penso que não deveria esperar o de 1970 - os censos em nosso país se realizam de 10 em 10 anos - para empregar êsse maravilhoso instrumento que permitirá simplificar de maneira quase inconcebível a apuração dos planos censitários que até agora estamos fazendo:

Nós, da Fundação Getúlio Vargas, por exemplo, consumidores de estatísticas, sabemos o quanto são deficientes, sob todos os aspectos, as estatísticas brasileiras. Basta que se diga que estamos em 1957 e ainda estão sendo publicados os resultados do Censo de 1950. Resultados desatualizados, de valor quase que puramente histórico, a não ser para certos estudos restropectivos dos aspectos econômicc's, sociais, demográficos, etc.

Ora, se nos preparássemos com tempo para utilização da automatização, pelo menos para aplicá-la no censo de 1960, poderíamos colhêr resultadc's extraordinários. Nenhum de nós pode prever o que seria para todos o estudo dos problemas brasileiros com a utilização dêsses novos equipamentos e métodos de trabalho, dando rendimento infinitamente maior do que os processc's até hoie usados, inclusive a mecanização já bastante difundida no Brasil. $\mathrm{E}$, mais do que isto, a existência dêsses equipamentos, dêsses métodos modernos de trabalho, permitiria que a planificação do Censo de 1960 fôsse muito mais ambiciosa, pois os elaboradcres dos planos censitários até agora contavam com sistemas anacrônicos e insuficientes de apuração e síntese de dados.

Cumpre, no entanto, assinalar um ponto: para que o Brasil possa usar, em 1960, a autcmatização, um prazo mínimo de preparo prévio de dois a três anos seria necessário, principalmente se levarmos em conta que a planificacão do censo já deverá ser feita tomando-se em consideráção as faciliđades tremendas da automatização para apuração e análise. São espetaculares as possibilidades da automatização. Essas máquinas são verdadeiros cérebros, a substituir cérebros humanos. Têm memória própria e são capazes de realizar proezas, como disse, verdadeiramente inconcebíveis para os cérebros já mais velhos como o meu...

Aproveito esta oportunidade, em que falo a um auditório tão alto sob todos os aspectos e de tão grande responsabilidade na vida pública brasi- 
leira, para fazer êste apêlo no sentido de que congreguemos esforços no sentido de trazer ao Brasil esta primeira equipe, que viria, pelo menos, mastrar-nos se é ou não possível pensarmos na utilização dos cérebros eletrônicos e da automatização de um modo geral no censo de 1960.

Segundo se depreende das palestras que ouvimos em Opatija, as possibilidades passam de muito às da apuração de um censo e portanto, poderíamos pensar na utilização da autcmatização em muitos setores da vida nacional. Mas quero ser mais modesto e objetivo. Se êsses especialistas nos dissessem, apenas, que a infra-estrutura administrativa e científica brasileira já permitiria (após trabalho intensivo de preparo) a utilização da automatização no censo de 1960 , já estariam a meu ver, fartamente compensadas as despesas e esforçcis com a vinda dêsses técnicos ao Brasil. Entretanto, se êles nos dissessem que poderíamos fazer o censo e, ainda, cutras tarefas, seria melhor ainda, evidentemente.

Quanto ao tema "tendências atuais com relação à transferência de podêres de autoridades maiores e autoridades menores delas separadas e viceversa", apresentaram trabalho por escritc a Alemanha, a Austrália, a Bélgica, o Brasil, o Canadá, a Espanha, a França, a India, a Iugoslávia, a Polônia e a União Soviética.

Êsse problema que vem preocupando os vários países mencionados é, em outras palavras, o que chamamos no Brasil a descentralizaçãc administrativa, matéria sempre atual, que vem preocupando profundamente a Comissão de Estudos e Projetos Administrativos da qual tenho a honra de ser o Presidente.

Estamos todos verificando que as autoridades superiores, a partir do Presidente da República, estão tôdas superlotadas de atribuições e encargos bürocráticos, que não só as impedem de exercer com proficiência a conhecimento de causa sua missão, como vêm perturbando a vida políticci-administrativa do país, forçando a população do interior a dirigir-se às mais altas autoridades para que vejam resolvidas questóes banais referentes à administração pública.

Êste problema está sendo sentido agudamente em vários países e muito justamente onde a centralização foi mais violenta, como na União Soviética. Os delegados soviéticos tiveram ocasião de divulgar em Opatija os programas do Govêrnc da União Soviética no sentido de promover; em larga escala, a descentralização da administração pública.

Entretanto, a essa idéia que hoje domina em quase todos os países, há forte oposição no meio brasileiro, onde as próprias autoridades querem ccncentrar cada vez mais em suas mãos funções que não podem exercer, desprestigiando os funcionários, desprestigiando vasta escala de autoridades que hoje não têm mais podêres para decidir coisa alguma e que se sentem tímidas em arcar com a responsabilidade das decisões, porque sabem que há sempre uma, duas, três ou quatro autoridades acima, sempre dispostas a rever suas decisões e anulá-las sob pressão de interessados ou de grupos. Isto ocorre porque a administraçãc entre nós está altamente centralizada.

Êste ponto, foi, portanto, um dos mais interessantes. Houve uma dificuldade inicial quanto ao que se devia considerar por descentralização, 
porque nas várias línguas o assuntc tinha acepções um pouco diferentes. Mas penso que chegamos todos a um entendimento através da nomenclatura inglêsa, "devolution of powers".

Dêsses debates também a delegação brasileira participou ativamente. Um problema fundamental foi focalizado pcr vários delegados: a manutenção do necessário equilíbrio entre as tendências para a centralização, por um lado, e para a "devolution of powers", por outro ladc. Como em tudo na vida, geralmente, a verdade está no meio. E' preciso haver um ponto de interseção, de onde se deve partir para um lado cu para outro: a descentralização ou a concentração de podêres, conforme a natureza dêles.

Outro ponto também muito interessante discutidos nessa Mesa-Redonda fci o sistema do mérito com relação à promoção.

E' uma das questões para a qual até hoje não se encontrou solução boa em nenhuma parte do mundo.

$\mathrm{Eu}$, que fui o responsável pela adotação do sistema de promoção pelo pracesso do mérito, como Presidente do Conselho Federal do Serviço Público Civil e, posteriormente, do D.A.S.P., através de atribuição de notas, tão criticado, sempre reconheci grandes falhas no sistema adotado pela legislação brasileira. Verifico porém, que, passados 20 anos, o problema está no statu qưo, isto é, não há solução conveniente, ninguém trouxe nenhuma novidade para melhorar a promoçãc por mérito.

Tôdas as sugestões lá apresentadas consubstanciavam as mesmas idéias, inclusive as tentadas no Brasil com relativo êxito e com as falhas que todos conhecemos: atribuição de pontos cu notas etc.

Nêste sentido, apresentaram trabalhos escritos o Brasil, a Espanha, a França, a India, a Itália e a União Soviética.

O trabalho do Relator se baseou na necessidade de ser o "mérito" o único critério para o progresso funcional dos servidores, quer se trate de promoção-pròpriamente dita, quer de simples aumento salarial. Para tal fim, a avaliação dc merecimento é o. método comumente usado, significando apreciação sistemática e organizada, dentro de determinado período de tempo do mérito do funcionário em causa, em relação a uma escala préestabelecida e sob vários pontos de vista. Prcpôs, finalmente, o Relator quatro pontos a discutir: a) os objetivos e a função da "avaliação"; $b$ ) os meios de aplicação da avaliação; $c$ ) os efeitos da avaliação e $d$ ) para eficiência do sistema, as precauções legais que devem ser adotadas para assegurar sua objetividade, bem como o direito a recurso nos casos de inexatidão, excesso ou abusc de autoridade.

Participaram dos debates o Brasil, a Cambódia, o Ceilão, a Espanha, os Estados Unidos, a França, a Grã-Bretanha, a India, a Itália, a Iugoslávia, a Libéria, Portugal, a Turquia e a União Soviética. Isso serve para mostrar cómo êsses pcntos ainda são controvertidos.

O resultado foi que a avaliação do merecimento foi considerada, quase unânimemente, como o processo técnico para a efetivação da promcição ou de simples aumento salarial. Mesmo nos casos em que a regra geral é a 
promoção por antiguidade, a avaliação de merecimentc surge como fator corretivo.

Esta foi uma observação um pouco nova para nós aqui no Brasil, porque a nossa promç̧ão por antiguidade é automática, o merecimento não interfere em nada. Apenas não se fará a promoção no sistema brasileiro se no interregno houver ocorrido fato novo que impeça a prcmoção.

Reconheceu-se que a avaliação do merecimento tem várias utilidades. Pode não só auxiliar as decisões sôbre promoção ou aumento salarial, como também as de muitas outras questões relacionadas com a carreira do funcionário público.

Verificou-se que as questões mais difíceis dizem respeito a método, atribuições e processamento. Na realidade, c assunto merece uma "MesaRedonda" especial.

Quanto às consequiências da avaliação, a opinião foi unânime no sentido de que, se não forem elas positivas, não vale a pena instituir o sistema - isto é, se da avaliação nada resulta, ela não deve ser feita.

$\mathrm{Um}$ dos mais importantes aspectos focalizados diz respeito aos fatôres a serem avaliados, e principalmente à questão de avaliar-se o "homem comc um todo" ou simplesmente o "funcionário".

Reconheceu-se, também, que geralmente a avaliação do merecimento deve estar sujeita a contrôles legais, embora não haja conclusões definitivas sôbre quais devam ser êles.

Voltando ao ponto da automatização, fci, a meu ver, a matéria mais interessante que surgiu na Mesa-Redonda. Os outros são temas que já vêm sendo considerados nos Congressos e Cunferências do próprio Instituto e de outras instituições nacionais e estrangeiras. Há uma vastíssima literatura sôbre êsses outros temas, especialmente nos Estados Unidos.

Sôbre a automatização falaram o Dr. RICHARD WESSLS, que é membro proeminente da Eurcpean Productivity Agency e pessoa muito qualificada na matéria; outra conferência que muito me impressionou foi feita por um representante francês, que tem vários trabalhos publicados e deve ser conhecido de muitos aqui presentes, o Sr. Lyonel WURMSER.

A grande vantagem da palestra do Sr. LyONEL WuRMSER é que êle com aquela clareza que é apanágio do gênio latino, da cultura francesa, conseguiu explicar com facilidade cousas que exigem profundo raciocínio das inteligências comuns, porém, de um modo tão perfeito, que acho que a grande maioria das pessoas presentes certamente saiu dali com uma noção bastante clara das imensas possibilidades que enseja o uso dessa nova conquista, traduzindo-se pelo aperfeiçoamento não só da administração pública mas de todos os setores das atividades humanas.

Também um representante da Alemanha e cutro da Itália falaram sôbre o assunto, descrevendo algumas experiências realizadas nos seus países.

O Brasil, em muitos campos, tem absorvido com rapidez as conquistas mais recentes, até mesmo no campo da administração pública. Por exem- 
plo, a mecanização de serviços que chamávamos, antigamente, cs "processos. Holerith", introduzidos no Brasil quando eram ainda novidade também nos. Estados Unidos. O Brasil ràpidamente se assenhoreou dessa técnica.

Senhor Presidente, tenho prazer em declarar que a delegação brasileira participou ativamente da mesa-redonda. Eu, na qualidade de VicePresidente do Instituto, participei ainda, das reuniões da Comissão Executiva, que dirige o Instituto. Penso que o Brasil está, agora, credenciado para ser a sede de uma mesa-redonda, ou mesmo de um congresso, porque é incontestável a liderança de nossa Pátria, nesse campc, na América Latina. Isto foi reconhecido, com grande isenção, pelos demais países latino-americanos, tanto que, espontâneamente, formaram em tôrno do Brasil para a Vice-Presidência do Instituto, quando são êles muito mais numerosos e po. deriam se congregar em tôrno de um candidato próprio de língua espanhola. A posição do Brasil penso que foi reconhecida pelos nossos amigos portuguêses e pelc's espanhóis, que também formaram nesta mesma linha, levantando a candidatura brasileira à Vice-Presidência.

Geralmente, há sempre, feitos por vários países, com grande antecedência, 5 ou 6 oferecimentos ao Instituto. O Instituto, então, entre aquelas ofertas, escolhe uma. De modo que a primeira fase para a realização de uma dessas reuniões no Brasil seria, justamente, um oferecimentc do Govêrno brasileiro ao Instituto.

Como alguns dos Senhores devem estar lembrados, já realizamos no Brasil, em 1952 uma mesa-redonda sôbre problemas de administração. Foi também, creio, a primeira mesá-redonda internacional realizada em tôda a América. Todavia, essa mesa-redonda não foi oficial, não foi o Govêrno brasileiro quem a realizou, nem o Instituto Internacional. Foi ela realisada scib os auspícios da Fundação Getúlio Vargas.

Tivemos cêrca de 70 pessoas, tôdas da mais alta qualificação. Provou, então, o Brasil, nessa ocasião, estar em condiçóes de realizar essa mesa-redonda.

No dia em que se abriu nossa mesá-redonda, os delegados estrangeiros presentes enccintraram grande quantidade de trabalhos publicados em português, espanhol, inglês e francês, quatro línguas portanto. Tratava-se de trabalhos feitos prèviamente, para serem discutidos por grupos especializados. Os resultados, ali, foram magníficos.

Ainda recentemente, há dias atrás, tive a ııonra de presidir a Delegação Brasileira à reunião que se realizou no Rio, a Reunião Inter-Americana de Normas Técnicas. Ncissa Delegação, graças aos esforços de PAulo SÁ e outros delegados patrícios, teve destacada atuação. Cito todos êsses exemplos apenas para justificar o ponto de vista em que me coloco, de que já estamos em ccndições e podemos, sem receio, aceitar a responsabilidade ce realizar uma mesa-redonda do Instituto aqui no Brasil. Já compareci a várias, como também os Drs. Carlos Medeiros e Themístocles CavalCANTI, nossos eminentes colegas, neste Conselho, pelo que estou certo de que no Brasil podemos fazer uma mesa-redonda, ou mesmo um congresso igual ou melhor do que a média dos congressos que o Instituto tem realizado. 
Talvez me tenha estendido um pouco demais, porque a matéria é bastante árida, mas, convidado pelo nosso Presidente para dar estas explicações, fui traído pelo interêsse que tenho pelo assunto. Muito obrigado.

O Sr. Marcial Dias Pequeno - Pediria a V. Ex. ${ }^{a}$ que dissesse uma palavra sôbre a agência brasileira do Instituto, o que, talvez por modéstia, tenha V. Ex. ${ }^{\text {a }}$ omitido.

Tenho grande interêsse até mesmo pelas publicações do Instituto, as quais tenho recebido de forma irregular e muito esparsas.

O Sr. Luís Simões Lopes - Com grande prazer.

A história do Instituto Brasileirc é a seguinte: durante o último govêrno do Presidente VARGaS, quando era Diretor do D.A.S.P. o Dr. ARízio Vianna, foi promovida a criação da seção brasileira, através do D.A.S.P. Mas foi feita de modo informal o que, a nossc ver, não correspondia exatamente ac que se deve ser uma seção nacional do Instituto. Foi publicada uma série de trabalhos, o Dr. ARízio Vianna, comparecendo com o Dr. CARLos MEDEIRos e outros, a diversas reuniões. Todavia, a seção brasileira não tinha organização condizente com as finalidades a que se propunha. Então, reuniram-se alguns interessados, inclusive os mesmos que tinham fundado a Primeira Seção Brasileira e todos, de comum acôrdo, resolvemos criar uma scciedade civil. Criamos, então, o Instituto Brasileiro de Ciências Administrativas. Promovemos, perante o Instituto Internacional, o reconhecimento dessa seção, como sendo a seção brasileira do Instituto Internacional. Como accntece sempre nos organismos internacionais, tôdas essas providências são muito lentas, de maneira que só recentemente a seção brasileira passou a ser, de fato, o Instituto Brasileiro de Ciências Administrativas. Criado o Instituto, eleita sua Diretoria, passamos imediatamente a congregar esforçcis, reunindo elementos de trabalho. Estamos, hoje, instalados no Edifício Darke, em local cedido pela Fundação Getúlio Vargas, de modo que estamos aptos a atender qualquer solicitação referente aos problemas do Instituto Internacicnal de Ciências Administrativas. A Revista do Instituto Internacional passou recentemente por grande transformação e hoje é, de fato um instrumento muito útil. A seção brasileira está pronta a ser a intermediária na tomada de assinatura da Revista, o que é uma forma prática e rápida de se conhecer tudo o que está sendo feito no mundo inteiro com relação aos problemas administrativos, de modo geral e principalmente nestes dois campos, o jurídico e o das práticas administrativas. 